\title{
Biosorption of Phenol and Cyanide from Synthetic/Simulated Wastewater by Sugarcane Bagasse-Equilibrium Isotherm and Kinetic Analyses
}

\author{
Neetu Singh ${ }^{1} \cdot$ Chandrajit Balomajumder $^{1}$
}

Received: 20 November 2016/Revised: 3 February 2017 / Accepted: 6 February 2017 /Published online: 23 February 2017

(C) Springer Science+Business Media Singapore 2017

\begin{abstract}
Sugarcane bagasse biosorbents were tested for biosorption of phenol and cyanide from synthetic/simulated wastewater. The influence of $\mathrm{pH}$, biosorbent dose, temperature, contact time, and initial concentration of phenol and cyanide was investigated. At an optimum temperature $30^{\circ} \mathrm{C}, \mathrm{pH}$ 7, and the biosorbent dose of $40 \mathrm{~g} / \mathrm{L}, 66.78 \%$ phenol and $79.30 \%$ cyanide were removed from binary aqueous solution containing $300 \mathrm{mg} / \mathrm{L}$ of phenol and $30 \mathrm{mg} / \mathrm{L}$ of cyanide. The equilibrium state was achieved after about 34 and $32 \mathrm{~h}$, respectively, for phenol and cyanide at a temperature of $30^{\circ} \mathrm{C}$. The extended Freundlich model fits the binary equilibrium data suitably for both phenol and cyanide. The kinetic modeling results showed that fractal-like models and BrouserWeron-Sototlongo for phenol and cyanide were capable to provide realistic explanation of biosorption kinetic. Biosorption of phenol and cyanide followed pseudo-secondorder kinetics, indicating chemisorption to be the mechanism of biosorption. The present study provides a new insight for the removal of phenol and cyanide onto sugarcane bagasse.
\end{abstract}

Keywords Cyanide $\cdot$ Isotherm modeling $\cdot$ Kinetic modeling $\cdot$ Phenol · Sugarcane bagasse

Electronic supplementary material The online version of this article (doi:10.1007/s41101-017-0019-1) contains supplementary material, which is available to authorized users.

Neetu Singh

neeturbs@gmail.com

Chandrajit Balomajumder

chandfch@iitr.ernet.in

1 Department of Chemical Engineering, Indian Institute of Technology, Roorkee, India

\section{Introduction}

Phenol and cyanide are discharged into an environment from numerous sources such as coke, iron-steel, pesticide, petroleum refining, mining, electroplating, wood-preserving chemicals, pharmaceuticals, and explosive-manufacturing industries [1-7]. Phenol and cyanide are measured persistent environmental pollutants, since they cannot degrade naturally. Exposure to even low concentrations of cyanide can cause heart pains, coma, breathing disorders, headaches, and even death. On the other hand, phenol exposure can lead to eye and skin injuries, headache, vomiting, lung, liver, kidney, and heart damage ultimately leading to death [8]. Therefore, it is important to remove phenol and cyanide from industrial wastewater and discharges. Both phenol and cyanide enter into water bodies due to unselective disposal of wastes from the industries $[2,5,9]$. Due to poisonous nature and environmental effects of phenol and cyanide, there are increasing to concerns for the removal of these pollutants from wastewaters [10-14]. The concentration of phenol and cyanide in the wastewater generated from industries is usually much above the allowable limit specified by environmental protection agencies. Therefore, environmental protection agencies of many countries have suggested acceptable limit for phenol and cyanide in effluent. US Environmental Protection Agency (US EPA) and Minimal National Standard (MINAS) of Central Pollution Control Board (CPCB) limits for phenol in effluent as $0.5 \mathrm{mg} / \mathrm{L}$ and for cyanide as $0.2 \mathrm{mg} / \mathrm{L}$ [2-5].

Various treatment technologies have been suggested for elimination of phenol and cyanide. These methods include such as biosorption, ion exchange, leaching, oxidization, precipitation, biodegradation, membrane separation, and solvent extraction. Among these treatment techniques, biosorption using agricultural waste material has increased significant 
attention because of its low cost, high efficiency, ease of handling, and more accessibility $[12,15]$. Biosorption process has been considered by many researchers as a substitute to conventional treatment methods for the elimination of phenol and cyanide from wastewater $[5,11,12,16]$.

Most of the studies revealed that agricultural waste either in natural form or modified form is highly effective for the removal of pollutants. Even more notably, agricultural wastes have usually minor carbon footprint in their consumption, comparatively free from extensive price variations. However, in current years, sugarcane bagasse (Saccharum officinarum L.), the solid fibrous material, generating after crushing of the sugarcane stalk and juice extracting, has established rare commercial uses. Some literature has been made to directly use sugarcane bagasse as an adsorbent for the wastewater treatment [15]. The sugarcane bagasse was used for the biosorption of phenol and cyanide from synthetic/simulated aqueous solution. The ability of sugarcane bagasse to eliminate phenol and cyanide was examined as functions of $\mathrm{pH}$, biosorbent dose, contact time, and initial concentration. The kinetic data of biosorption studies were verified using 14 kinetic models. The equilibrium data of biosorption studies were confirmed using five monocomponent isotherm models and six binary component isotherm models. The field emission -scanning electron microscopy (FE-SEM) and Fourier transform infrared (FTIR) analyses before and after biosorption of phenol and cyanide onto sugarcane bagasse were also carried out to estimate the adsorption mechanism. The proposed model provides a better description of the biosorption of phenol and cyanide in the liquid phase. It is our belief that till date, our group has employed this biosorbent for simultaneous biosorption of phenol and cyanide in the liquid phase.

The purposes of the current study, distributed into four parts, were (1) to characterize the prepared fresh biosorbent (sugarcane bagasse) before and after loading with SEM and FTIR; (2) to examine the influence of operating parameters, viz., $\mathrm{pH}$, contact time, biosorbent dose, temperature, and initial concentration for eliminating phenol and cyanide from synthetic/simulated wastewater; (3) to estimate the kinetics and mechanism of present biosorption process; and (4) to study the isotherms of biosorption to determine the mechanism of biosorption process.

\section{Materials and Methods}

\section{Reagents}

All AR-grade chemicals were used without further treatment and supplied by HiMedia Laboratories Pvt. Mumbai, India. Stock solution containing $100 \mathrm{mg} / \mathrm{L}$ cyanide was prepared by dissolving $0.0189 \mathrm{~g}$ of $\mathrm{NaCN}$ in $1 \mathrm{~L}$ of Millipore water (Q$\mathrm{H}_{2} \mathrm{O}$, Millipore Corp. with resistivity of $18.2 \mathrm{MX} \mathrm{cm}$ ). Stock solution comprising $1000 \mathrm{mg} / \mathrm{L}$ of phenol was prepared by dissolving $1 \mathrm{~g}$ of pure phenol crystal in $1 \mathrm{~L}$ of Millipore water. The test solutions of various concentrations were prepared by diluting the stock solution [14].

\section{Biosorbent Collection and Preparation}

Sugarcane bagasse was collected from the local sugar mill. Sugarcane bagasse was washed with hot water $\left(60^{\circ} \mathrm{C}\right)$ and dried in sunlight followed by oven dried at $60{ }^{\circ} \mathrm{C}$ for $72 \mathrm{~h}$. Biosorbent was soaked in $2 \mathrm{~N} \mathrm{H}_{2} \mathrm{SO}_{4}$ solution to protonate the adsorption sites available on sugarcane bagasse surface [12]. The biosorbent was then washed several times with Millipore water and dried in hot air oven at $60{ }^{\circ} \mathrm{C}$ for $12 \mathrm{~h}$ to completely remove moisture. The dried sugarcane bagasse was sieved and stored in airtight plastic containers for further experimentation.

\section{Biosorption Experiment}

To study the biosorption as a function of dose $0.5-60 \mathrm{~g} / \mathrm{L}$ of sugarcane bagasse for phenol and cyanide was considered, and $\mathrm{pH}(8)$, contact time $(40 \mathrm{~h})$, temperature $\left(30^{\circ} \mathrm{C}\right)$, and initial concentration $(300 \mathrm{mg} / \mathrm{L}$ of phenol and $30 \mathrm{mg} / \mathrm{L}$ of cyanide) were kept constant. To evaluate the effect of $\mathrm{pH}, 2$ $12 \mathrm{pH}$ range was used, whereas biosorbent dose, contact time temperature, and initial concentrations were kept constant. The effect of temperature was measured in the range of 20 $50^{\circ} \mathrm{C}$. To evaluate equilibrium isotherm, the initial concentrations of phenol and cyanide, $100-1000 \mathrm{mg} / \mathrm{L}$ of phenol and $10-100 \mathrm{mg} / \mathrm{L}$ of cyanide concentrations, were used, while $40-$ $\mathrm{g} / \mathrm{L}$ biomass dose, $\mathrm{pH} 8$, temperature $30^{\circ} \mathrm{C}$, and contact time $40 \mathrm{~h}$ were constant $[13,14]$. The contact time ranging from 2 to $50 \mathrm{~h}$ was used to evaluate kinetic modeling study, while other parameters were kept constant. Initial concentrations of phenol and cyanide were maintained at 300 and $30 \mathrm{mg} / \mathrm{L}$, respectively, except in those where the initial phenol and cyanide concentration effects are to be studied. The volume of synthetic/simulated aqueous solution $(100 \mathrm{~mL})$, shaking speed $(120 \mathrm{rpm})$, and biosorbent particle size $(0.25 \mathrm{~mm})$ were kept constant in all batch experiments [14]. The all batch experiments were carried out in a $250-\mathrm{mL}$ round bottom flask with a working volume of $100 \mathrm{~mL}$ at $120 \mathrm{rpm}$ in an incubator cum orbital shaker (Metrex, MO-250, India). The residual phenol and cyanide concentration were analyzed by colorimetric picric acid and 4-aminoantipyrene methods, respectively, by UV-Vis spectrophotometer (Hach, USA) [17].

The amount of phenol and cyanide adsorbed onto sugarcane bagasse was calculated by the concentration difference method $[5,15]$. The biosorption capacities of sugarcane bagasse of phenol and cyanide were predicted using the amount of pollutant retained on unit mass of biosorbent. 
The total amount of phenol and cyanide adsorbed per unit mass of the biosorbent at equilibrium $\left(Q_{e}\right)$ and at time $t\left(Q_{t}\right)$ was designed by using the following equation:

$Q_{e}=\left(C_{i}-C_{e}\right) V / M$

$Q_{t}=\left(C_{i}-C_{t}\right) V / M$

The percent removal of phenol and cyanide was calculated as follows:

Percentage removal $=\left(\left(C_{i}-C_{f}\right) / C_{i}\right) \times 100$

where

$Q_{e} \quad$ is the amounts of phenol and cyanide adsorbed on to the per unit mass of biosorbent at equilibrium $(\mathrm{mg} / \mathrm{g})$,

$Q_{t} \quad$ is the uptake of phenol and cyanide at time $t(\mathrm{mg} / \mathrm{g})$,

$\mathrm{C}_{\mathrm{f}}$ is the final concentration of phenol and cyanide $(\mathrm{mg} / \mathrm{L})$,

$\mathrm{C}_{\mathrm{t}}$ is the liquid phase concentration of phenol and cyanide at time $t(\mathrm{~h})$,

$\mathrm{C}_{\mathrm{i}}$ is the initial pollutant concentration ( $\left.\mathrm{mg} / \mathrm{L}\right)$,

$\mathrm{C}_{\mathrm{e}}$ is the concentration of adsorbate at equilibrium $(\mathrm{mg} / \mathrm{L})$,

$\mathrm{V}$ is the volume of the solution (L),

$\mathrm{M}$ is the mass of the biosorbent $(\mathrm{g})$.

\section{Surface Analysis of Biosorbent}

To determine the surface morphology of sugarcane bagasse and its composition, FE-SEM (FE-SEM Quanta 200 FEG) analytical instrument was used. The biosorbent before and after biosorption of phenol and cyanide was subjected to analysis by the instrument. The elemental analysis for sugarcane bagasse was also conducted by energy-dispersive X-ray spectroscopy. Spectral analysis using FTIR (Nicolet 6700, USA, coupled with OMNIC software version 6.2) was used to explain the functional groups present onto the surface of the sugarcane bagasse before and after biosorption. The characterization of biomass was achieved by proximate and ultimate analyses. The proximate analysis of biomass provides volatile content, moisture content, free residual carbon, ash content in the sample, and high heating value, whereas the ultimate analysis provides information about the weight percentage of hydrogen, carbon, and oxygen as well as nitrogen and sulfur [18]. Table 1 shows the proximate and ultimate analyses of sugarcane bagasse. The Brunauer-EmmettTeller (BET) surface area of sugarcane bagasse is $67 \mathrm{~m}^{2} /$ g. The technique for estimating surface area is the BET method [19].

\section{Isotherm and Kinetic Analyses}

To design an adsorption system, it is important to establish the most appropriate correlation for the equilibrium curves.
Table 1 Proximate and ultimate analyses of sugarcane bagasse

Sugarcane bagasse (wt\%)

\begin{tabular}{ll} 
A. Proximate analysis & \\
Moisture & 8.1 \\
Fixed carbon & 12.5 \\
Volatile matter & 82.1 \\
Ash content & 3.9 \\
Heating value $\left(\mathrm{MJ} \mathrm{kg}^{-1}\right)$ & 18.5 \\
B. Ultimate analysis & \\
Carbon & 43.8 \\
Hydrogen & 5.23 \\
Oxygen & 45.4 \\
Nitrogen & 0.34 \\
Sulfur & 0.01 \\
Calorific value $(\mathrm{kcal} / \mathrm{kg})$ & 4410 \\
\hline
\end{tabular}

Therefore, the equilibrium adsorption data for phenol and cyanide from mono-component and binary component systems onto sugarcane bagasse have been used to test the applicability of various mono- and multi-component isotherm equations. The equilibrium data of biosorption studies were confirmed using five mono-component isotherm models (Langmuir, Freundlich, Redlich-Peterson, Toth, and Fritz-Schlunder ) and six binary component isotherm models (non-modified Langmuir, modified Langmuir, extended Langmuir, extended Freundlich, non-modified Redlich-Peterson, and modified Redlich-Peterson models). The kinetic data of biosorption studies were verified using 14 kinetic models (fractional power model; pseudo-first order; pseudo-second order; Elovich model; Avrami model; modified second-order model; Ritchie second-order model; exponential kinetic model; mixed first-, second-order model; fractal-like mixed first-, second-order model; fractal-like first-order model; fractallike second-order model; fractal-like exponential model; and Brouser-Weron-Sototlongo mode).

\section{Results and Discussion}

\section{Biosorbent Characterization}

\section{FE-SEM Analysis of Sugarcane Bagasse}

Sugarcane bagasse is a non-conducting biomaterial. Unloaded and loaded samples were also visualized through SEM to take into account the changes in surface morphology due to the adsorption of phenol and cyanide. For scanning electron microscopy analysis, biosorbent was coated with gold in the occurrence of argon. The images were taken with an 
Fig. 1 Surface micrographs of sugarcane bagasse samples a before biosorption and $\mathbf{b}$ after biosorption (FE-SEM analysis)
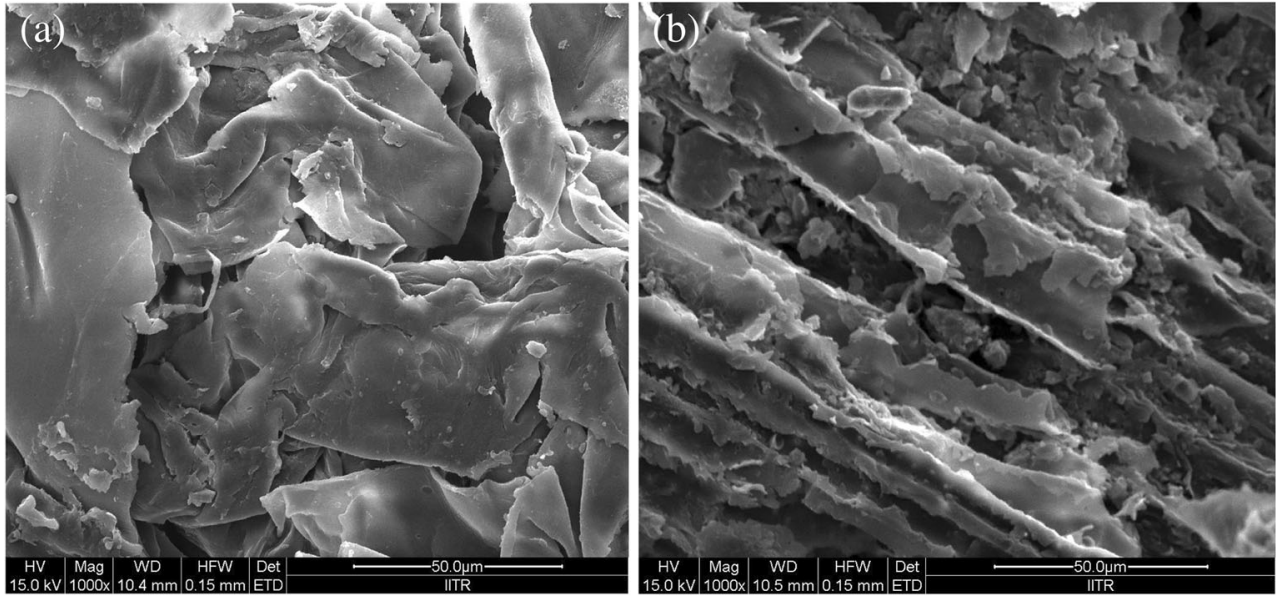

accelerator voltage $=15 \mathrm{kV}$ and an emission current $=1001 \mathrm{~A}$ by the tungsten filament. The surface morphologies of sugarcane bagasse are revealed in Fig. 1a, b. A change in surface morphology from being smooth to rough and occupation of pores indicates biosorption of phenol and cyanide onto the surface and pores of sugarcane bagasse giving it a rough texture (Fig. 1b).

\section{FTIR Spectroscopy of Sugarcane Bagasse}

To understand the biosorption process, chemical structure of the biosorbent is of significant importance. For identifying the functional group's presence on biosorbent surface, the FTIR method is a significant tool. The samples of sugarcane bagasse were taken before and after biosorption and dried at $60{ }^{\circ} \mathrm{C}$ in an oven. The pellet to be analyzed was obtained by compressing a mixture of sample and KBR in a ratio of 1:10 in hydraulic press at 15-t pressure for $30 \mathrm{~s}$. The FTIR spectra of sugarcane bagasse are revealed in Fig. 2. Several strong and weak peaks were detected in the region of $4000-400 \mathrm{~cm}^{-1}$. The region between 3125 and $3575 \mathrm{~cm}^{-1}$ indicated the stretching of $\mathrm{O}-\mathrm{H}$ from cellulosic basis [20]. The peak detected at $3299.87 \mathrm{~cm}^{-1}$ was recognized as $\mathrm{O}-\mathrm{H}$ stretching, which shifted to $3310.76 \mathrm{~cm}^{-1}$ after phenol and cyanide biosorption. The peak at $2536.76 \mathrm{~cm}^{-1}$ is indicated carboxyl group. The FTIR spectra showed broad peaks at about $1612.34 \mathrm{~cm}^{-1}$, conforming to stretching from ketones and aldehydes. The band in the area of about $1600 \mathrm{~cm}^{-1}$ indicated the occurrence of carbonaceous materials. Therefore, a stretch detected at $1612.34 \mathrm{~cm}^{-1}$ seemed in Fig. 2 [21]. The peaks at about $589.76 \mathrm{~cm}^{-1}$ show the occurrence of $\mathrm{Si}-\mathrm{H}$. Peak at $1612.34 \mathrm{~cm}^{-1}$ corresponds to $-\mathrm{CH}$ stretching due to the presence of conjugated hydrocarbon groups, aromatic hydrocarbons, carboxylic groups, and carboxyl and carbonate structures indicating adsorption of phenol, whereas peak at $1345.44 \mathrm{~cm}^{-1}$ corresponds to inorganic nitrates marking a potential adsorption site for cyanides. It could be detected from Fig. 2 that some peaks are shifted and broadened,
Fig. 2 FTIR spectra of sugarcane bagasse before and after biosorption

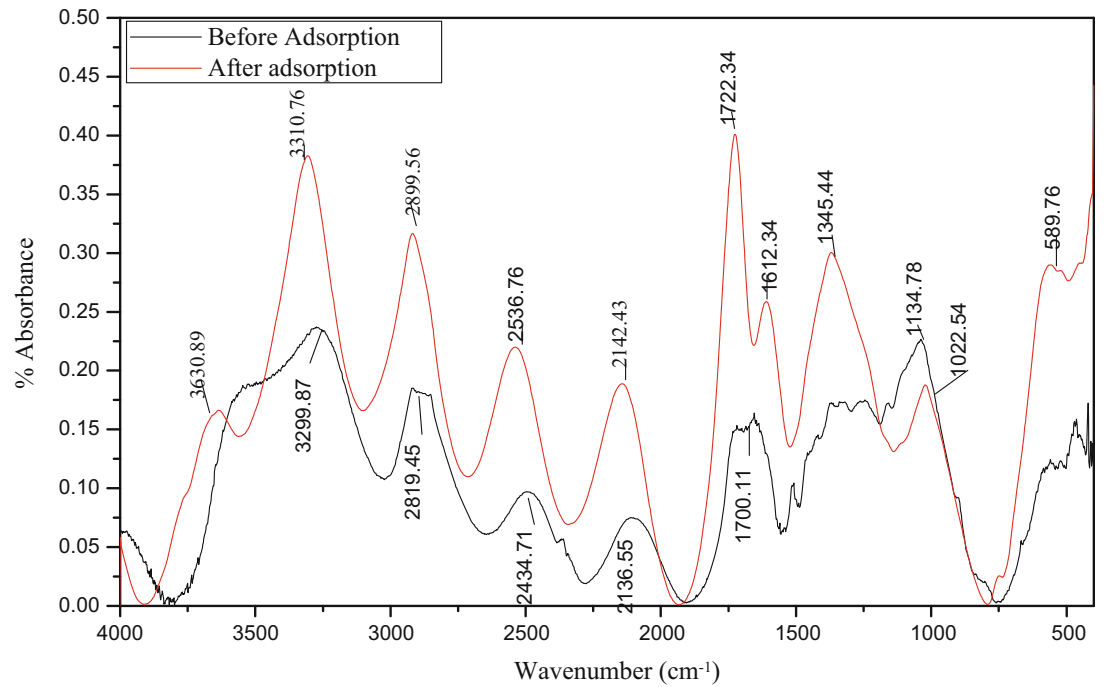


representing that the functional groups existing on the sugarcane bagasse surface were involved in biosorption of phenol and cyanide.

\section{Effect of Operating Parameters}

\section{Effect of $p H$}

Figure 3 illustrates the effect of biosorption on phenol and cyanide removal efficiency. The $\mathrm{pH}$ of the biosorption system significantly influences the pollutant ion speciation, surface chemistry of the biosorbent surface, and adsorption of adsorbate onto adsorbent surface. At acidic $\mathrm{pH}$ range (4-7), the cyanide removal rate is high. The percentage removal of cyanide increases with the increase in $\mathrm{pH}$ up to $\mathrm{pH} 7$. Beyond $\mathrm{pH}$ 7 , the removal percentage of cyanide becomes constant. Sugarcane bagasse generally contains some anionic groups such as carbonyl, phenolic, and phosphate, which are accountable for negative surface charge on the sugarcane bagasse. Sugarcane bagasse also comprises oxides like $\mathrm{CaO}, \mathrm{SiO}_{2}$, and $\mathrm{Al}_{2} \mathrm{O}_{3}$. These oxides reacts with $\mathrm{H}^{+}$or $\mathrm{OH}^{-}$and $\mathrm{S}^{-}$ions of the aqueous solution and can produce both negative and positive charges on the biosorbent surface. As in sugarcane bagasse, the concentration of $\mathrm{CaO}$ is high; at $\mathrm{pH}<7.0$, biosorbent surfaces reveal positive charge and responsible in the biosorption of cyanide [15, 22]. The biosorption of cyanide is due to the surface charges on biosorbent surface and cyanide behavior in water. At $\mathrm{pH}$ values above 7.0, high negative surface charge grows on the biosorbent surface. The increase in biosorption of cyanide was observed beyond $\mathrm{pH}$ 7 in $\mathrm{NaCN}$ solution. Higher adsorption of cyanide occurred in $\mathrm{pH}$ range of 7-10 [23]. This is owing to the fact that cyanide is hydrolyzed in aqueous solution to form $\mathrm{HCN}$. The pKa value of hydrocyanic acid is 9.4 . So, at $\mathrm{pH}<9.4$, cyanide exists in $\mathrm{HCN}$; however, at $\mathrm{pH}>9.4, \mathrm{HCN}$ dissociates to $\mathrm{CN}-$ ions

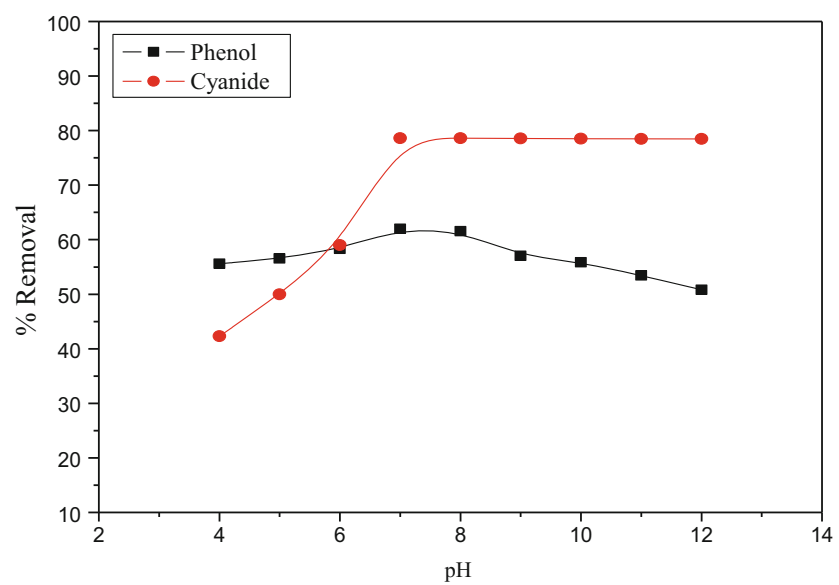

Fig. 3 Effect of pH on the biosorption of $300 \mathrm{mg} / \mathrm{L}$ of phenol and $30 \mathrm{mg} /$ $\mathrm{L}$ of cyanide using $40 \mathrm{~g} / \mathrm{L}$ sugarcane bagasse, during orbital shaking of $120 \mathrm{rpm}$ at $30^{\circ} \mathrm{C}$ temperature for $40 \mathrm{~h}$
[24]. Since $\mathrm{CN}-$ is a nucleophilic ion and when in interaction with the negatively charged biosorbent, it fixes with the anionic functional groups existing on the biosorbent surface and thus increases rate of biosorption. Figure 3 signifies that the biosorption of phenol remains nearly constant in an acidic $\mathrm{pH}$ range, where the phenol remains in undissociated forms. Phenol is a weak acid with acid dissociation value (pKa) of 9.8, and it dissociates into phenoxide ion when $\mathrm{pH}>\mathrm{pKa}$. At lower $\mathrm{pH}$ values, phenolic compounds are present as the unionized acidic compound [25]. However, a reduction is observed in percentage removal at $\mathrm{pH}$ greater than its $\mathrm{pKa}$ (9.96), representing the biosorption of phenol in its undissociated form and $\mathrm{pH} 7$ to be most suitable for biosorption of phenol [25]. However, as the $\mathrm{pH}$ increased, the biosorption start to decrease likely owing to the electrostatic repulsions between the negatively charged phenol anion and the surface site or by the phenol anions in the aqueous solution [26]. All further batch studies were achieved at $\mathrm{pH} 7$, which is the optimum value for both the phenol and cyanide.

\section{Effect of Biosorbent Dose}

Figure 4 indicates the effect of biosorbent dose on percentage removal of phenol and cyanide in the range of $0.5-60 \mathrm{~g} / \mathrm{L}$. The percentage removal of both phenol and cyanide increases with an increase in biosorbent dose up to $40 \mathrm{~g} / \mathrm{L}$, and beyond this dose, the percentage removal becomes constant. This is due to the fact that the phenol and cyanide concentrations onto biosorbent surface and concentrations of phenol and cyanide in solution come into equilibrium with each other. The increase in removal percentage of phenol and cyanide at initial stage is owing to the increase in biosorbent dose. This is owing to fact that with the increase in biosorbent dose, the number of active sites on the biosorbent surface in unit volume of aqueous solution increases; thus, there is an increase in the removal percentage of phenol and cyanide. Therefore, the

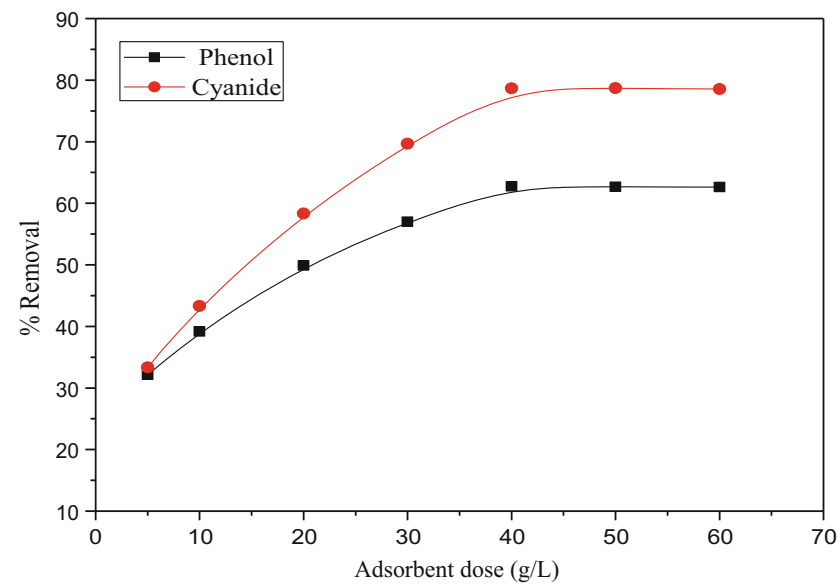

Fig. 4 Effect of biosorbent dose on the biosorption of $300 \mathrm{mg} / \mathrm{L}$ of phenol and $30 \mathrm{mg} / \mathrm{L}$ of cyanide using $\mathrm{pH} 7$, during orbital shaking of $120 \mathrm{rpm}$ at $30^{\circ} \mathrm{C}$ temperature for $40 \mathrm{~h}$ 
Fig. 5 Effect of contact time on the biosorption of $300 \mathrm{mg} / \mathrm{L}$ of phenol and $30 \mathrm{mg} / \mathrm{L}$ of cyanide using $\mathrm{pH} 7$, biosorbent dose $40 \mathrm{~g} /$ L during orbital shaking of $120 \mathrm{rpm}$ at $30^{\circ} \mathrm{C}$ temperature

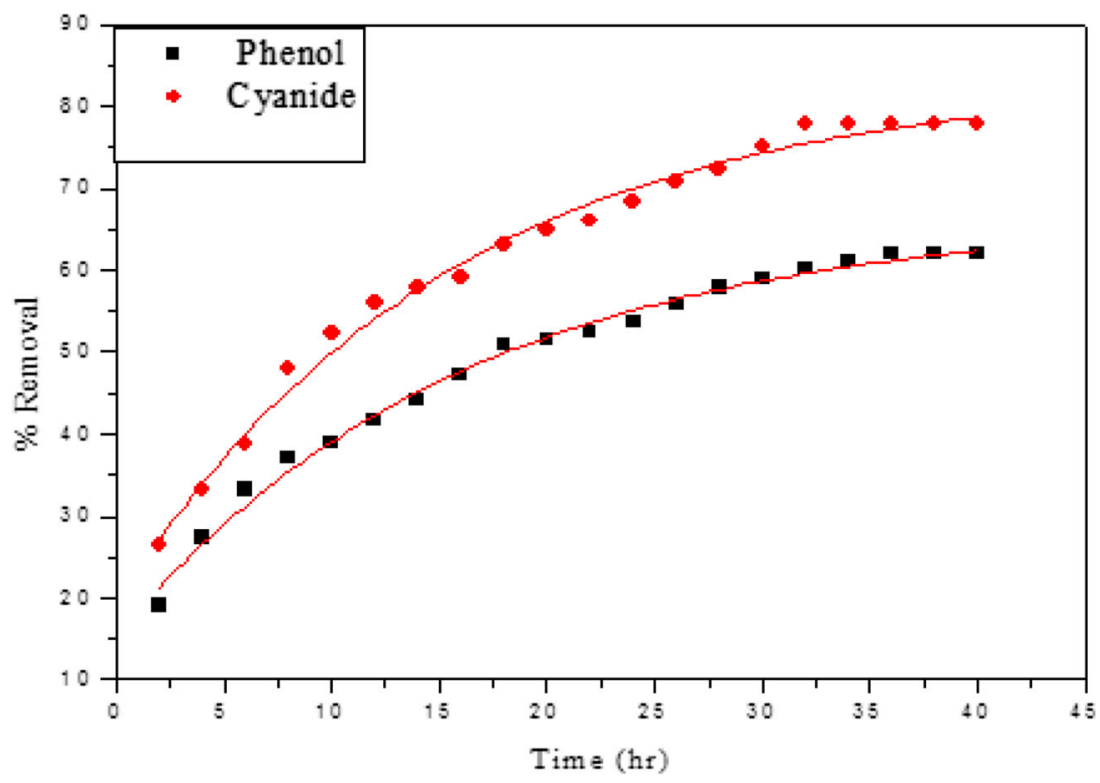

optimum dose of sugarcane bagasse for removal of phenol and cyanide can be chosen as $40 \mathrm{~g} / \mathrm{L}$ for biosorption process.

\section{Effect of Contact Time}

The biosorption data for the percentage removal of phenol and cyanide versus contact time are revealed in Fig. 5. The removal percentage of both phenol and cyanide were fast at the initial stage of biosorption process, owing to fact that at initial stage, more sites were available for biosorption, and as time passes, the rest of biosorption sites were hard to be adsorbed for the reason that of repulsive forces between molecules of bulk phase and solid [26]. The mass transfer resistance between biosorbent and bulk phase is overcome through energy provide by contact time. This energy is used to transfer substrate species from bulk solution to the energetic sites existing on biosorbent surface; as a result, at initial stage of process, the percentage removal of phenol and cyanide is high. The figure indicates that the percentage removal becomes constant after $34 \mathrm{~h}$ in the case of phenol and $32 \mathrm{~h}$ in the case of cyanide.

\section{Effect of Temperature}

Figure 6 shows the results achieved from phenol and cyanide biosorption when temperature was increased from 20 to $40{ }^{\circ} \mathrm{C}$. The percentage removal increases from 56.31 to 58.52 and from 58.67 to $80.33 \%$ in case of phenol and cyanide, respectively, on increasing temperature of phenol and cyanide from 20 to $40{ }^{\circ} \mathrm{C}$ (Fig. 6). As the temperature rises, the rate of diffusion of the phenol and cyanide molecules through the exterior boundary layer and in the inner pores of the biosorbent increase due to the reduction in the viscosity of the aqueous solution. The thermal energy of molecules also increases with temperature. The increasing of temperature may enhance the affinity of aggregation and therefore the uptake of the phenol and cyanide [5]. The removal of cyanide is increased up to $30{ }^{\circ} \mathrm{C}$ slightly, and after that, it becomes constant. Biosorption of phenol was decreased with increasing temperature (Fig. 6). This could be due to the increased tendency of desorption of phenol at increased temperature, resulting owing to weakening of adsorptive forces between adsorbate and active sites of adsorbent as well as between the nearby molecules of adsorbate [15]. A decrease and constant in the adsorption rate of both cyanide and phenol, respectively, with increasing temperature are related to the increasing Brownian movement of molecules in solution [27]. The optimum temperature of the aqueous binary solution was carefully chosen as $30{ }^{\circ} \mathrm{C}$ for both phenol and cyanide.

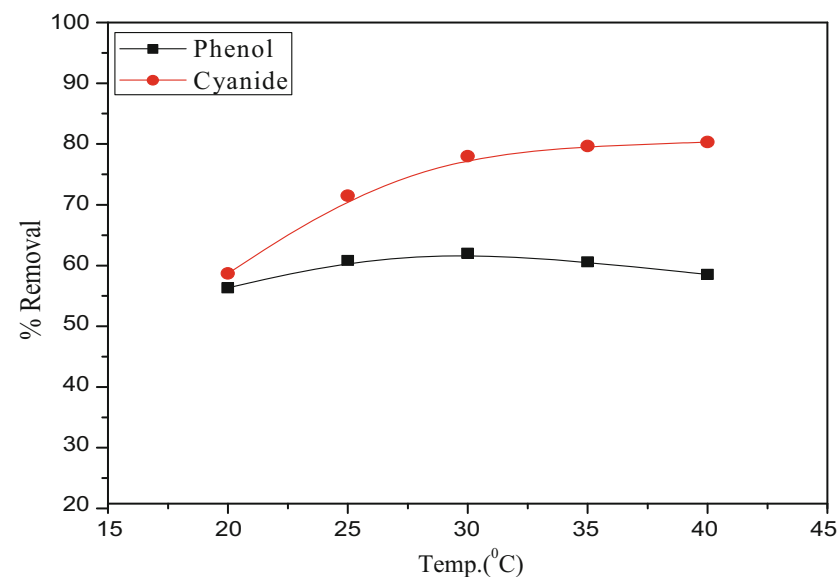

Fig. 6 Effect of temperature on the biosorption of $300 \mathrm{mg} / \mathrm{L}$ of phenol and $30 \mathrm{mg} / \mathrm{L}$ of cyanide using $\mathrm{pH} 7$, biosorbent dose $40 \mathrm{~g} / \mathrm{L}$ during orbital shaking of $120 \mathrm{rpm}$ for $40 \mathrm{~h}$ 


\section{Effect of Initial Concentrations of Phenol and Cyanide}

The effect of initial concentrations of phenol and cyanide on biosorption was evaluated from 100 to $1000 \mathrm{mg} / \mathrm{L}$ of phenol and $10-100 \mathrm{mg} / \mathrm{L}$ of cyanide, and the additional operating parameters such as shaking speed (120 rpm), biosorbent dose (40 g/L), pH (7), and contact time ( $40 \mathrm{~h})$ remain constant. The percentage removal of phenol and cyanide onto sugarcane bagasse were found to decrease at higher concentrations. The surface of sugarcane bagasse turn out to be saturated after some time; as a result, the removal percentage is higher at initial stage of operation. This is owing to the fact that at initial stage, the enough number of active binding sites is vacant on the surface of biosorbent. But, at higher initial concentrations, the number of phenol and cyanide ions are comparatively high than existing biosorption sites on the surface of sugarcane bagasse. A similar statement has been well defined by Mondal and Balomajumder (2007) [22]. When the initial concentration of phenol was increased from 100 to $1000 \mathrm{mg} / \mathrm{L}$, the uptake capacity increased from 1.5 to $5.64 \mathrm{mg} / \mathrm{g}$ and the percentage removal decreased from 75.00 to $28.21 \mathrm{mg} / \mathrm{L}$ for sugarcane bagasse (Fig. 7a). In case of cyanide, similar tendency was detected. The percentage removal was decreased from 81.01 to $43.87 \mathrm{mg} / \mathrm{L}$ for the initial cyanide concentration of $10-100 \mathrm{mg} / \mathrm{L}$, and uptake capacity increased from 0.16 to $0.88 \mathrm{mg} / \mathrm{g}$ (Fig. 7b).

\section{Equilibrium Isotherm Modeling}

The comparisons of equilibrium isotherm models for phenol and cyanide onto sugarcane bagasse are presented in Figs. 8 and 9. The equilibrium isotherm data were fitted into the several mono- and multi-component isotherm models (Table 2). Mono-component isotherm modeling was carried out to find the best fit model and estimation of parameters for multi-component adsorption studies. The best model is chosen on the basis of error function Marquardt's percent standard deviation (MPSD).

\section{Mono-Component Modeling}

The individual Langmuir, Freundlich, Redlich-Peterson, Toth, and Fritz-Schlunder isotherm model parameters for phenol and cyanide were studied to explain the biosorption process. Out of these isotherms, Langmuir and Freundlich are two-parameter models, Redlich-Peterson and Toth are threeparameter models, and Fritz-Schlunder model is fourparameter model. Langmuir model relies on the assumptions that a mono-layer of biosorbate is biosorbed above homogenous surface of biosorbent at a constant temperature, there is no contact between the biosorbed molecules and all vacant sites on biosorbent surface, and all active sites are of same intensity [28]. The Freundlich model is based on biosorption on heterogeneous surfaces [28]. Redlich and Peterson model include three parameters into an isotherm and then can be applied both in heterogeneous or homogenous systems, owing to the high adaptability of the equation [29]. The FritzSchlunder model is empirical three-parameter isotherm combining the Langmuir and Freundlich isotherms [29]. The parameters of the five mono-component isotherms and the values of their corresponding MPSD are presented in Table 2, whereas Fig. 8 offers the comparison between the isotherm models for phenol and cyanide. When the initial concentration increases from 10 to $100 \mathrm{mg} / \mathrm{L}$ for cyanide (a)

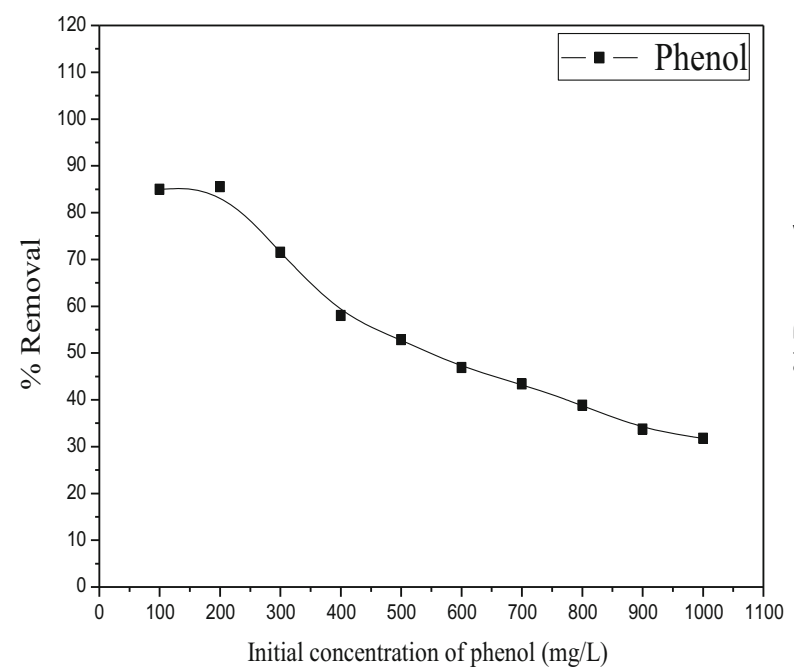

(b)

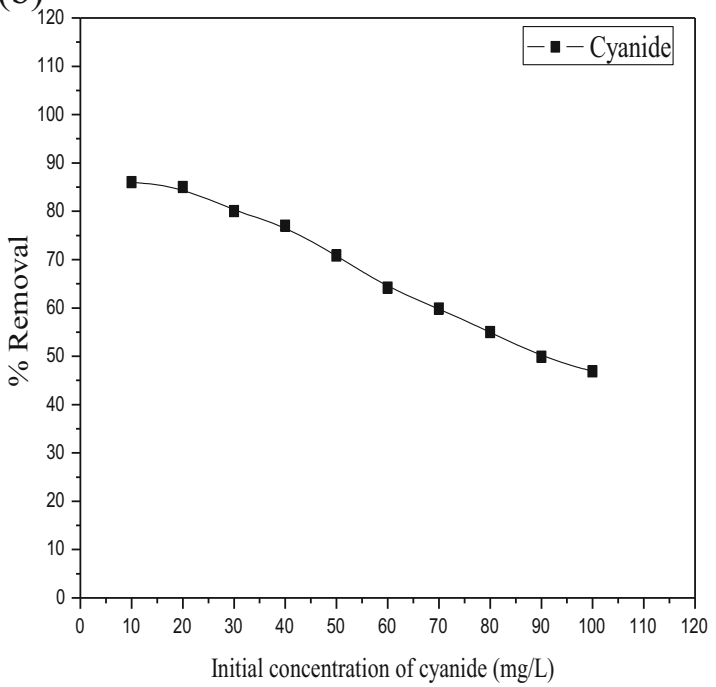

Fig. 7 Effect of initial concentration on the biosorption of phenol and cyanide using $\mathrm{pH}$ 7, biosorbent dose $40 \mathrm{~g} / \mathrm{L}$ during orbital shaking of $120 \mathrm{rpm}$ at $30{ }^{\circ} \mathrm{C}$ temperature for $40 \mathrm{~h}$ contact time. a Phenol. b Cyanide 
(a)

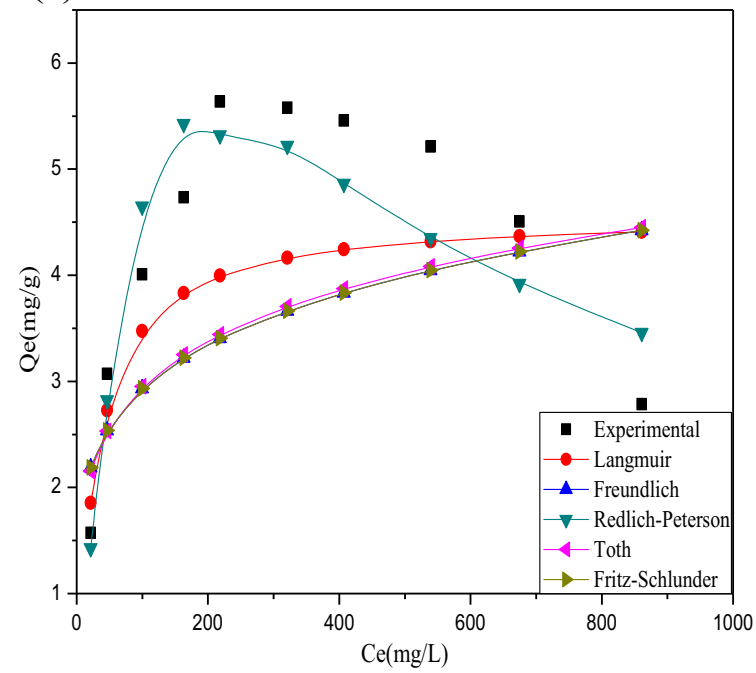

(b)

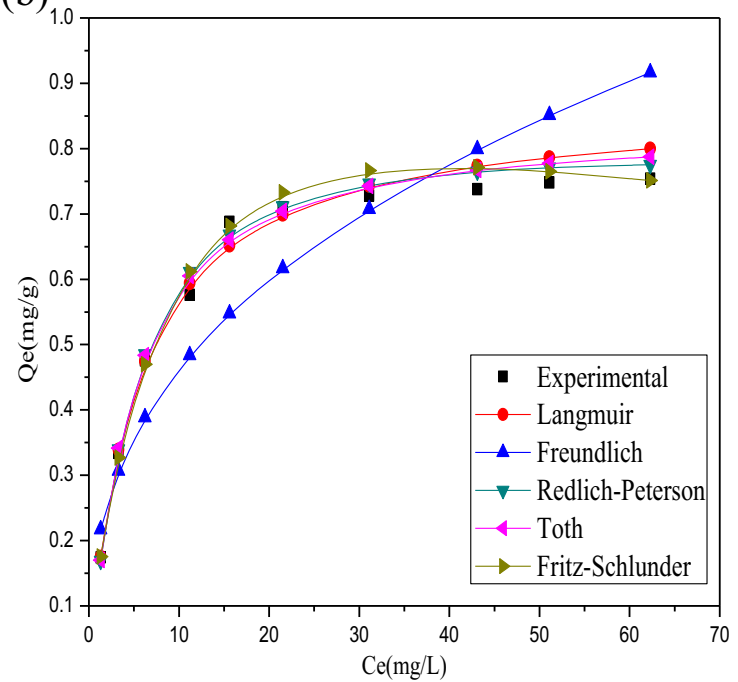

Fig. 8 Comparison of different mono-component isotherm models on sugarcane bagasse. a Phenol. b Cyanide

and 100 to $1000 \mathrm{mg} / \mathrm{L}$ for phenol, the biosorption capacity of sugarcane bagasse increases from 0.17 to $0.75 \mathrm{mg} / \mathrm{g}$ for cyanide and from 1.57 to $4.50 \mathrm{mg} / \mathrm{g}$ for phenol in monocomponent system. The initial concentration provides the necessary driving force to overcome the resistances to the mass transfer of phenol and cyanide between the aqueous and the solid phases. The increase in initial concentration also increases the interaction between the pollutant in the aqueous phase and the sugarcane bagasse [28]. Therefore, an increase in initial concentration of phenol and cyanide enhances the adsorption uptake of the phenol and cyanide. Also, it is observed that the adsorption capacity of bagasse for phenol is greater than that for cyanide. The main purpose to carry out single-component adsorption studies is to evaluate the best model among the abovementioned models and to estimate the parameters of the models used in binary component adsorption studies. Based on the results revealed in Table 2 and Fig. 8, best fit isotherm models for phenol are observed in the order of Redlich-Peterson > Langmuir $>$ Toth $>$ FritzSchlunder $>$ Freundlich and for cyanide in the order of Fritz-Schlunder $>$ Redlich-Peterson $>$ Toth $>$ Langmuir $>$ Freundlich. $K_{F}$ and $n$, the mono-component Freundlich constants, show the adsorption capacity and adsorption intensity, respectively. The higher the value of $n$ is, the higher will be the affinity and the heterogeneity of the biosorbent surface are. It is found from Table 2 that the sugarcane bagasse shows greater heterogeneity for phenol than that for cyanide. Between the two-parameter model, the Langmuir model provides a better (a)

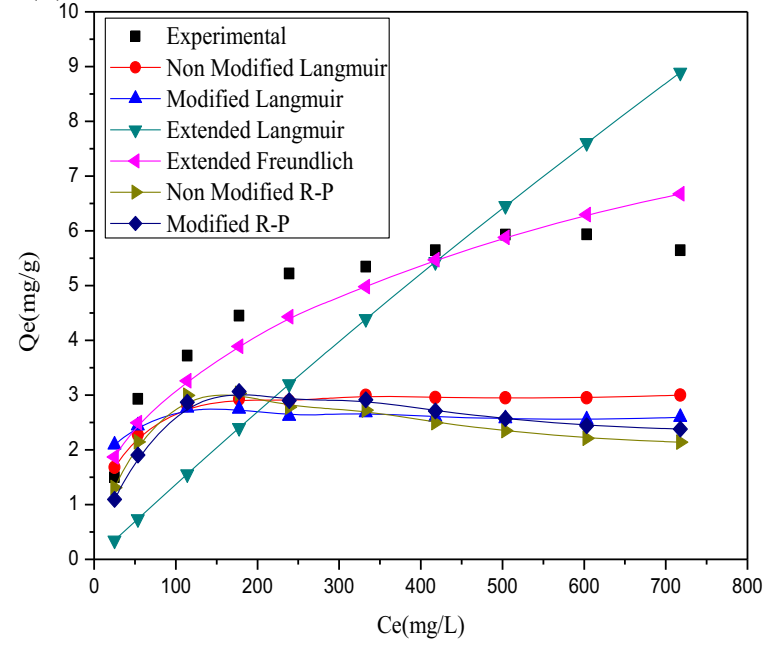

(b)

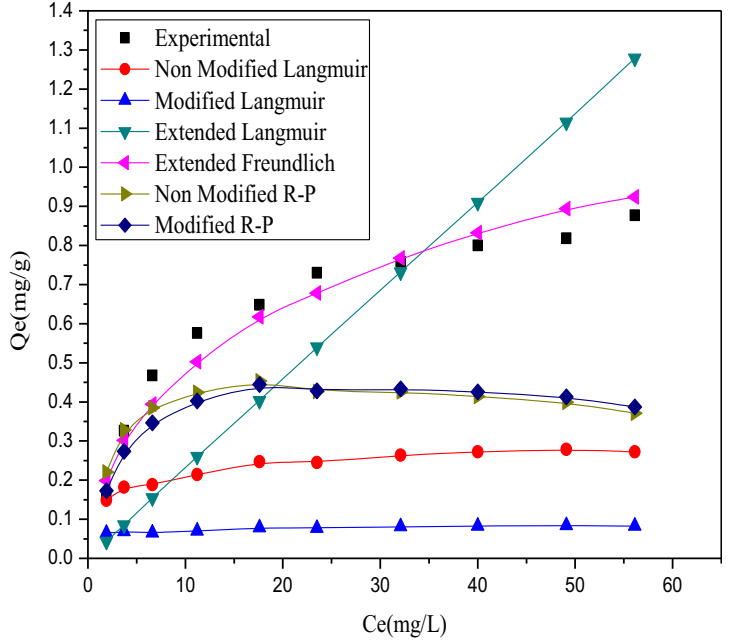

Fig. 9 Comparison of different binary component isotherm models on sugarcane bagasse. a Phenol. b Cyanide 
fit than the Freundlich model. The features of Langmuir isotherms can be described by a separation factor [30].

$R_{L}=\frac{1}{\left(1+b C_{0}\right)}$

Separation factor $R_{L}$ explains the feasibility of adsorption process. An adsorption process is favorable when $R_{L}<1$, unfavorable when $R_{L}>1$, linear when $R_{L}=1$, favorable for $0<R_{L}<1$, and irreversible when $R_{L}=0$. In this study, the value of $R_{L}$ was found to be 0.10 and 0.14 , respectively, for phenol and cyanide. This shows a greatly favorable biosorption $(R<1)$.

\section{Binary Component Modeling}

The presence of more than one component in an aqueous solution causes interference and competition for adsorption sites, which leads to a more complex mathematical formulation of the equilibrium. In general, amount of component adsorbed may increase, decrease, or remain unchanged in the presence of other component(s). Therefore, the relationships between the adsorbed quantity of one component and the concentrations of all other components present in the aqueous solution are described by multi-component adsorption isotherms [23]. The binary component experimental adsorption data of phenol and cyanide onto sugarcane bagasse have been examined by non-modified Langmuir model, modified Langmuir model, extended Langmuir, extended Freundlich model, non-modified R-P model, and modified R-P model. The values of model parameters with MPSD are specified in Table 2. The comparisons of binary component models for phenol and cyanide in the aqueous solution are shown in Fig. 9a, b. The binary component extended Freundlich model indicates a better fit to the experimental data with a low MPSD value for both phenol and cyanide $(\mathrm{MPSD}=14.96$ and MPSD $=12.14$, respectively). This is predictable as sugarcane bagasse has a heterogeneous surface. It is evident that the modification of the Freundlich equation as given by the extended Freundlich model takes into account the interactive effects of individual pollutant between and among themselves and also the biosorbent sugarcane bagasse reasonably well. Therefore, the binary adsorption of phenol and cyanide onto sugarcane bagasse can be represented satisfactorily and effectively by the extended Freundlich model. The values of the correction factors are less than 1.0 for modified Langmuir model (Table 2), representing that the modified Langmuir model could predict the binary adsorption equilibrium data [31]. When the initial concentration increases from 10 to $100 \mathrm{mg} / \mathrm{L}$ for cyanide and 100 to $1000 \mathrm{mg} / \mathrm{L}$ for phenol, the loading capacity of sugarcane baggase increases from 0.16 to $0.88 \mathrm{mg} / \mathrm{g}$ for cyanide and from 1.50 to $5.64 \mathrm{mg} / \mathrm{g}$ for phenol in binary
Table 2 Comparison of mono-component and binary component isotherm model parameters for phenol and cyanide onto sugarcane bagasse

\begin{tabular}{|c|c|c|c|}
\hline & Parameters & Phenol & Cyanide \\
\hline \multicolumn{4}{|c|}{ Mono-component isotherm models } \\
\hline \multirow[t]{3}{*}{ Langmuir } & $Q_{o}$ & 4.57 & 0.87 \\
\hline & $b$ & 0.03 & 0.20 \\
\hline & MPSD & 29.46 & 5.09 \\
\hline \multirow[t]{3}{*}{ Freundlich } & $K_{F}$ & 1.22 & 0.19 \\
\hline & $n$ & 5.25 & 2.69 \\
\hline & MPSD & 37.94 & 18.67 \\
\hline \multirow[t]{4}{*}{ Redlich-Peterson } & $K_{\mathrm{RP}}$ & 0.069 & 0.15 \\
\hline & $a_{\mathrm{RP}}$ & 0.0003 & 0.13 \\
\hline & $\beta$ & 1.63 & 1.06 \\
\hline & MPSD & 15.73 & 4.43 \\
\hline \multirow[t]{4}{*}{ Toth model } & $q_{\mathrm{to}}$ & 282.04 & 0.83 \\
\hline & $a$ & 0.31 & 6.94 \\
\hline & $n$ & 0.048 & 1.15 \\
\hline & MPSD & 37.47 & 4.78 \\
\hline \multirow[t]{5}{*}{ Fritz-Schlunder model } & $a_{1}$ & 0.58 & 4.32 \\
\hline & $a_{2}$ & -0.53 & 28.59 \\
\hline & $b_{1}$ & 0.19 & -0.36 \\
\hline & $b_{2}$ & -0.0005 & -1.11 \\
\hline & MPSD & 37.90 & 3.45 \\
\hline \multicolumn{4}{|c|}{ Binary component isotherm models } \\
\hline Non-modified Langmuir & MPSD & 44.54 & 66.60 \\
\hline \multirow[t]{2}{*}{ Modified Langmuir } & $\eta_{i, j}$ & 0.37 & 0.34 \\
\hline & MPSD & 51.50 & 80.69 \\
\hline \multirow[t]{3}{*}{ Extended Langmuir } & $Q_{o, i}$ & 94.25 & 5.46 \\
\hline & $b_{i}$ & 0.0001 & 0.0003 \\
\hline & MPSD & 53.58 & 54.79 \\
\hline \multirow[t]{4}{*}{ Extended Freundlich } & $x_{i}$ & -0.49 & -0.48 \\
\hline & $y_{i}$ & 1.17 & 0.11 \\
\hline & $z_{i}$ & -0.13 & 0.40 \\
\hline & MPSD & 14.96 & 12.14 \\
\hline Non-modified R-P model & MPSD & 51.72 & 43.51 \\
\hline \multirow[t]{2}{*}{ Modified R-P model } & $n_{i, j}$ & 1.29 & 1.37 \\
\hline & MPSD & 50.27 & 42.11 \\
\hline
\end{tabular}

component system. Biosorption of phenol followed the trend of better fit models as extended Langmuir $<$ non-modified Redlich-Peterson $<$ modified Langmuir $<$ modified Redlich Peterson $<$ non-modified Langmuir $<$ extended Freundlich, whereas biosorption of cyanide followed the trend as modified Langmuir < non-modified Langmuir < extended Langmuir $<$ non-modified Redlich Peterson $<$ modified Redlich Peterson < extended Freundlich. Comparisons of specific uptake for biosorption of phenol and cyanide on different biosorbents are shown in Table 3 .

In binary component aqueous solution, the components present in solution may have three types of sorption interaction effects such as if the adsorption of the adsorbate decrease when there are additional adsorbates present in the binary component mixture (antagonism $Q_{\text {mix }} / Q_{i}<1$ ), the adsorption of the adsorbate increase when there are another adsorbates present in the binary component mixture (synergism $Q_{\text {mix }} /$ $Q_{i}>1$ ), and if the binary component mixture has no effect on the adsorption of each adsorbate (non-interaction $Q_{\text {mix }} /$ $Q_{i}=1$ ) [32], where $Q_{i}$ is the biosorption capacity of 
Table 3 Comparison of specific uptake for biosorption of phenol and cyanide on different biosorbents

\begin{tabular}{|c|c|c|c|c|c|}
\hline Serial no. & Biosorbent & $\begin{array}{l}\text { Initial concentration } \\
(\mathrm{mg} / \mathrm{L})\end{array}$ & $\begin{array}{l}\text { Specific uptake } \\
(\mathrm{mg} / \mathrm{g})\end{array}$ & Component & Reference \\
\hline 1 & Activated carbon & 200 & 28.2 & Cyanide & {$[24]$} \\
\hline 2 & $\begin{array}{l}\text { Lignified activated carbon and iron impregnated activated } \\
\text { carbon derived from Gölbas, lignite }\end{array}$ & 100,100 & $64.02,62.04$ & Cyanide & [39] \\
\hline 3 & Moderate density fiber board saw dust (MDFSD) & 100 & 1.4 & Cyanide & {$[40]$} \\
\hline 4 & Pistachio green hull & 156 & 1.56 & Cyanide & {$[41]$} \\
\hline 5 & $\begin{array}{l}\text { Rice husk, activated carbon, impregnated activated carbon } \\
\text { by silver and copper }\end{array}$ & 100 & 0.401 & Cyanide & {$[42]$} \\
\hline 6 & Lantana camara & 250 & 25 & Phenol & {$[14]$} \\
\hline 7 & Olive mill waste & 700 & 25 & Phenol & {$[43]$} \\
\hline 8 & Modified fly ash & $30-80$ & 30 & Phenol & {$[44]$} \\
\hline 9 & Sugarcane bagasse fly ash & 200 & 30 & Phenol & {$[15]$} \\
\hline 10 & Sugarcane bagasse & 300 & 94.24 & Phenol & Current study \\
\hline 11 & Sugarcane bagasse & 30 & 5.46 & Cyanide & Current study \\
\hline
\end{tabular}

component present alone in the solution and $Q_{\text {mix }}$ is the bisorption capacity of one component in the presence of the other component in binary component aqueous solution. The values of $Q_{\text {mix }} / Q_{i}$ are establish to be 20.62 for phenol and 6.27 for cyanide as existing in Table 2, founding the fact that both phenol and cyanide show synergism effects.

The experimental equilibrium sorption data obtained for the mono-component and the binary systems show that the adsorption capacity of sugarcane bagasse for phenol is, in general, more than that of cyanide. There are possible interaction effects between different pollutants in the solution and, in specific, possible interactions on the surface depending on the adsorption mechanism. The factors that affect the sorption preference of biosorbent for different kinds of adsorbates may be associated to the characteristics of the binding sites (e.g., surface properties, functional groups, and structure), the properties of the adsorbates (e.g., ionic size, concentration, ionic weight, molecular structure, ionic charge, ionic nature, or standard redox potential), and the solution chemistry (e.g., ionic strength, and $\mathrm{pH}$ ). Though, it is difficult to find a common denominator from the physical and chemical properties of phenol and cyanide, which describes the interactive mechanism and the increase in the selectivity for sorption of an adsorbate from the binary mixtures.

\section{Kinetic Modeling}

Kinetic modeling was recognized in order to found the mechanism of biosorption onto biosorbents. Kinetic study distributes the fact about the mechanism of biosorption that includes the diffusion (external, intraparticle, and bulk) and chemical reactions. In general, the adsorbate transport follows in the few steps: (1) the transport of pollutants in the bulk solution, (2) the external diffusion from the bulk solution to the exterior surface of the biosorbent, (3) the transport of the pollutant through the boundary layer, (4) the transfer of pollutant in the pores of the biosorbent and finally uptake of pollutant molecules by the active sites, and (5) the biosorption and desorption of pollutant [33]. To estimate the dynamic biosorption behavior of phenol and cyanide on sugarcane bagasse, numerous kinetic models were used in this study, assuming that concentrations of adsorbate on the adsorbent surface are equal to the measured concentrations. (The details of kinetic equations are provided in the supplementary material.) Among them, fractional power model, pseudo-first order, and pseudo-second order are empirical models, though their major shortcoming is that they may only define the adsorption kinetics at some situations [34]. Elovich kinetic model, fractional power, Ritchie second order, and exponential kinetic models are two-parametric empirical models to analyze kinetic data. Other three-parametric kinetic models, for example, Avrami; modified pseudo-second-order; and mixed first-, second-order equations, have been suggested for adsorption kinetics at the solid/solution interface.

A non-linear regression analysis technique was used to solve adsorption kinetic models. Table 4 demonstrates the values of kinetic model parameters for the biosorption of phenol and cyanide on surface of sugarcane bagasse. The best fit model was determined on the basis of error function MPSD. High error values recommend that these models (pseudo-first order, Avrami, and exponential) are not appropriate for both phenol and cyanide. On the basis of the lowest error function values of MPSD, the perfect fitting of the experimental results was achieved by using Brouser-Weron-Sototlongo model and fractal-like models such as fractal-like pseudo-first order; fractal-like pseudo-second order; fractal-like exponential; and fractal-like mixed first, second order (Fig. 10a, b) for both phenol and cyanide among all the tried kinetic models.

The better fit of Brouser-Weron-Sototlongo kinetic model specifies that the removal of both phenol and cyanide onto 
Table 4 Kinetic model parameters for biosorption of phenol and cyanide onto sugarcane bagasse

\begin{tabular}{|c|c|c|c|}
\hline Kinetic models & Parameters & Phenol & Cyanide \\
\hline \multirow[t]{3}{*}{ Fractional power model } & $k_{\mathrm{fp}}$ & 1.59 & 0.21 \\
\hline & $v$ & 0.39 & 0.37 \\
\hline & MPSD & 0.85 & 0.94 \\
\hline \multirow[t]{3}{*}{ Pseudo-first order } & $q_{e}$ & 5.72 & 0.72 \\
\hline & $k_{1}$ & 0.15 & 0.15 \\
\hline & MPSD & 1.96 & 1.99 \\
\hline \multirow[t]{3}{*}{ Pseudo-second order } & $q_{e}$ & 6.93 & 0.87 \\
\hline & $k_{2}$ & 0.023 & 0.19 \\
\hline & MPSD & 1.132 & 1.29 \\
\hline \multirow[t]{3}{*}{ Elovich model } & $a_{\mathrm{el}}$ & 1.71 & 5.31 \\
\hline & $b_{\mathrm{el}}$ & 0.59 & 4.79 \\
\hline & MPSD & 0.49 & 0.80 \\
\hline \multirow[t]{4}{*}{ Avrami model } & $q_{e}$ & 5.72 & 0.72 \\
\hline & $k_{\mathrm{av}}$ & 0.26 & 0.37 \\
\hline & $n_{\mathrm{av}}$ & 0.55 & 0.40 \\
\hline & MPSD & 1.96 & 1.99 \\
\hline \multirow[t]{4}{*}{ Modified second-order model } & $q_{e}$ & 7.96 & 1.016 \\
\hline & $k_{1 m}$ & 0.09 & 0.084 \\
\hline & $b_{1 m}$ & 1.15 & 1.17 \\
\hline & MPSD & 0.52 & 0.62 \\
\hline \multirow[t]{3}{*}{ Ritchie second-order model } & $q_{e}$ & 6.93 & 0.87 \\
\hline & $k_{1 R}$ & 0.16 & 0.16 \\
\hline & MPSD & 1.13 & 1.29 \\
\hline \multirow[t]{3}{*}{ Exponential kinetic model } & $q_{e}$ & 5.92 & 0.75 \\
\hline & $k_{\mathrm{ex}}$ & 0.097 & 0.099 \\
\hline & MPSD & 1.49 & 1.59 \\
\hline \multirow[t]{4}{*}{ Mixed first-, second-order model } & $q_{e}$ & 6.79 & 0.87 \\
\hline & $k_{m}$ & 0.0046 & 0.003 \\
\hline & $f_{2}$ & 0.97 & 0.98 \\
\hline & MPSD & 1.13 & 1.29 \\
\hline \multirow[t]{5}{*}{ Fractal-like mixed first-, second-order model } & $q_{e}$ & 7.72 & 0.97 \\
\hline & $f_{\mathrm{eq}}$ & -18.38 & -13.16 \\
\hline & $k_{\mathrm{fm}}$ & 1.68 & 1.48 \\
\hline & $\alpha$ & 0.26 & 0.28 \\
\hline & MPSD & 0.48 & 0.66 \\
\hline \multirow[t]{4}{*}{ Fractal-like, first-order model } & $q_{e}$ & 8.05 & 1.03 \\
\hline & $k_{\mathrm{ff}}$ & -0.18 & -0.19 \\
\hline & $a$ & 0.57 & 0.55 \\
\hline & MPSD & 0.45 & 0.69 \\
\hline \multirow[t]{4}{*}{ Fractal-like, second-order model } & $q_{e}$ & 10.83 & 1.44 \\
\hline & $k_{\mathrm{fs}}$ & 0.013 & 0.10 \\
\hline & $a$ & 0.63 & 0.59 \\
\hline & MPSD & 0.45 & 0.71 \\
\hline \multirow[t]{4}{*}{ Fractal-like exponential model } & $q_{e}$ & 8.55 & 1.12 \\
\hline & $k_{\text {fex }}$ & 0.10 & 0.11 \\
\hline & $a$ & 0.62 & 0.59 \\
\hline & MPSD & 0.45 & 0.70 \\
\hline \multirow[t]{5}{*}{ Brouser-Weron-Sototlongo model } & $q_{e}$ & 11.19 & 0.93 \\
\hline & $t_{\mathrm{bws}, \alpha}$ & 23.82 & 14.63 \\
\hline & $n_{\mathrm{bws}}$ & 1.98 & 2.25 \\
\hline & $a^{2}$ & 0.59 & 1.22 \\
\hline & MPSD & 0.45 & 0.60 \\
\hline
\end{tabular}

sugarcane bagasse followed chemisorption interaction type, indicating that the rate-controlling step might be chemical adsorption including valency forces over exchange or distribution of electrons between phenol and cyanide anions and sugarcane bagasse. Additionally, the Brouser-Weron-Sototlongo kinetic model states other notable data, which is the time significantly to adsorb half the maximum amount $\left(t_{\mathrm{bws}, \alpha}\right)$. Brouser-WeronSototlongo kinetic model has a good fitting performance; it states such quality data (i.e., biosorption capacity close to experimental data, $q_{e}$ (BWS), and the time of half reaction $\left(t_{\mathrm{bws}, \alpha}\right)[35,36]$. As presented in Table 3 , with respect to initial phenol and cyanide concentrations, 23.82 and $14.63 \mathrm{~h}$ (the lowest value) were suitable for sugarcane bagasse to achieve half of the phenol and cyanide uptake capacities, respectively, which is important as well as valuable parameter for computing the reaction speed. As for BWS model itself, it has a good fitting performance and more implicitly, which were estimated aimed at industrial treatment design purposes [36]. Avrami 
(a)

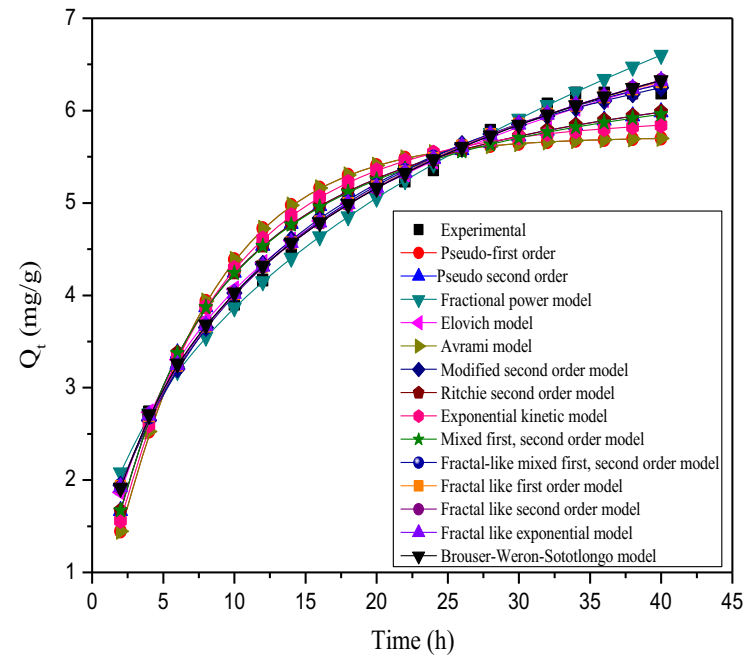

(b)

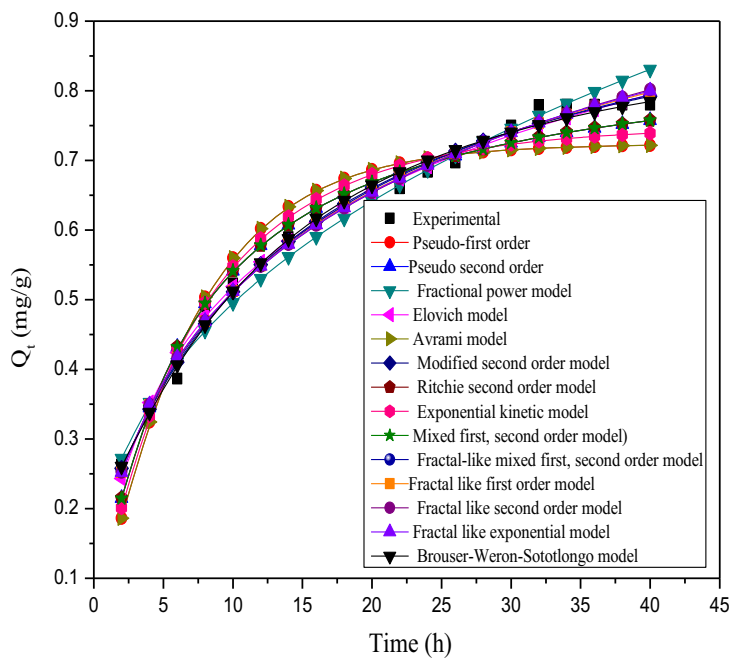

Fig. 10 Comparison of kinetic models for biosorption onto the sugarcane bagasse. a Phenol. b Cyanide

exponent $\left(n_{\text {av }}\right)(0.55$ for phenol and 0.40 for cyanide) is a fractionary number connected with the possible variations of the biosorption mechanism that happens all over the biosorption process $[37,38]$. The value of low error values (MPSD) for pseudo-second-order model estimates that possible route or mechanism of biosorption of phenol and cyanide on sugarcane bagasse is chemisorption. It is understood that the mixed first-, second-order rate equation is linear in the Lagergren coordinates near to the equilibrium and slightly in the initial portion of the experiment. Specifically, we may conclude that it contains two linear sections linked with a curved one. The second-order equation shows linear performance in the initial stage of the experiment also; however, the linear section is relatively short. On the other hand, mixed first-, second-order rate equation may be treated as Langmuir equation for energetically homogeneous surfaces or as only empirical equation for energetically heterogeneous surfaces. The vital theory of modified second-order model was that a number of surface sites are used by both phenol and cyanide. It was supposed that the pre-adsorbed phase occurred on sugarcane bagasse biosorption. The vital theory of Ritchie second-order model was that one adsorbate was adsorbed on two surface sites. It was supposed that the pre-adsorbed phase has not occurred on sugarcane bagasse biosorption. The sugarcane bagasse surface cover age has been usually supposed to be zero. For fractal-like models such as fractal-like pseudo-first order; fractal-like pseudo-second order; fractal-like exponential; and fractal-like mixed first, second order, the rate coefficient for biosorption is measured as a function of time by using the fractal-like idea. One of the probable physical meanings of fractal-like kinetics was that biosorption of phenol and cyanide occurred at solid/solution edge. In this methodology, it was specified that by passing time, a number of paths for phenol and cyanide biosorption on biosorbent surface seems [35]. The error values MPSD for fractal-like models and BrouserWeron-Sototlongo kinetic model were better than that other kinetic models for phenol and cyanide. Fractal-like mixed first-, second-order kinetic model representing the rate of adsorption was dependent on initial concentration of adsorbate in solution and rate of agitation. Also, on the basis of the fractal-like concept, the fractal-like equations can be used for investigating the kinetic data for biosorption systems with heterogeneous solid surfaces. However, the Brouser-Weron-Sototlongo kinetic model revealed the complex mechanism of removal process. Figure 10a, b demonstrates the comparison of kinetic models for phenol and cyanide removal, respectively.

\section{Conclusions}

The current study demonstrates that the sugarcane bagasse is an effective biosorbent for the elimination of phenol and cyanide from synthetic/simulated wastewater. Maximum biosorption for both $300 \mathrm{mg} / \mathrm{L}$ of phenol and $30 \mathrm{mg} / \mathrm{L}$ of cyanide was found to occur at $\mathrm{pH} 7.0$, biosorbent dose $40 \mathrm{~g} /$ $\mathrm{L}$, and temperature $30^{\circ} \mathrm{C}$. The Redlich-Peterson model and Fritz-Schlunder model for phenol and cyanide, respectively, indicate good fit with the experimental equilibrium data for mono-component aqueous solution. In the binary component solution, the affinity of the sugarcane bagasse for phenol was greater than that for cyanide, for both the mono-component and binary component solutions under the similar experimental environment. On the basis of MPSD error function, the extended Freundlich equilibrium isotherm model revealed the best fit to the binary component data. The effect of presence of phenol and cyanide on each other was also calculated, and it was found to be synergistic. By applying 14 kinetic models, the Brouser-Weron-Sototlongo model and fractal- 
like models such as fractal-like pseudo-first order; fractal-like pseudo-second order; fractal-like exponential; and fractal-like mixed first-, second-order models were found suitable for predicting the kinetic of biosorption of both phenol and cyanide onto sugarcane bagasse. The kinetic study experimental data also indicated better fit with pseudo-second-order model very well; therefore, it can be established that chemisorption was the potential route of biosorption on sugarcane bagasse. In conclusion, it may be established that sugarcane bagasse may be used for the separate and simultaneous elimination of phenol and cyanide from synthetic/simulated wastewater.

$Q_{o}$, Langmuir model constant (mg/g); $b$, Langmuir model constant; $Q_{e, i}$, amount of $i$ th component adsorbed per gram of adsorbent at equilibrium $(\mathrm{mg} / \mathrm{g}) ; Q_{o, i}$, constant in modified Langmuir model for $i$ th component $(\mathrm{mg} / \mathrm{g}) ; C_{e, i}$, concentration of $i$ th component in the binary mixture at equilibrium $(\mathrm{mg} / \mathrm{L})$; $K_{F}$, Freundlich model constant (mg/g); $n$, Freundlich, Toth model constant; $K_{F, i}$, extended Freundlich model constant $(\mathrm{mg} / \mathrm{g}) ; K_{\mathrm{RP}}$, Redlich-Peterson model constant $(\mathrm{L} / \mathrm{g}) ; a_{\mathrm{RP}}$, Redlich-Peterson model constant (L/mg); $\beta$, RedlichPeterson model constant; $\eta_{\mathrm{RP}, i}$, binary component RedlichPeterson model constant $(\mathrm{L} / \mathrm{g}) ; a_{\mathrm{RP}, i}$, binary component Redlich-Peterson model constant ( $\mathrm{L} / \mathrm{mg}) ; \beta_{j}$, binary component Redlich-Peterson model constant; $x_{i}, y_{i}, z_{i}$, constant in modified Redlich-Peterson model; $N$, number of observations in the experimental isotherm; $P$, number of parameter in regression model; $Q_{e, i}^{\text {exp }}$, experimental value of $Q_{e}(\mathrm{mg} / \mathrm{g}) ; Q_{e, i}^{\text {cal }}$, predicted value of $Q_{e}(\mathrm{mg} / \mathrm{g}) ; \alpha_{1}$, constant in Fritz-Schlunder isotherm $(\mathrm{mg} / \mathrm{g}) /(\mathrm{mg} / \mathrm{L})^{\beta 1} ; \alpha_{2}$, constant in Fritz-Schlunder isotherm $(\mathrm{mg} / \mathrm{L})-\beta_{2} ; \beta_{1}, \beta_{2}$, constants in Fritz-Schlunder isotherm; $k_{\mathrm{fp}}$, fractional power model rate constant ( $\left.\mathrm{mg} \mathrm{g}^{-1} \mathrm{~h}^{-1}\right) ; v$, adjustment parameter; $k_{1}$, pseudo-first-order adsorption rate constant $\left(\mathrm{h}^{-1}\right) ; k_{2}$, pseudo-second-order adsorption rate constant $\left(\mathrm{g} \mathrm{mg}^{-1} \mathrm{~h}^{-1}\right) ; a_{\mathrm{el}}$, Elovich coefficient representing the initial adsorption rate $\left(\mathrm{g} \mathrm{mg}^{-1} \mathrm{~h}^{-1}\right) ; b_{\mathrm{el}}$, Elovich coefficient representing desorption constant $\left(\mathrm{g} \mathrm{mg}^{-1}\right) ; k_{\mathrm{av}}$, Avrami kinetic rate coefficient $\left(\mathrm{h}^{-1}\right) ; n_{\mathrm{av}}$, constant corresponding to the mechanism of adsorption; $k_{1 m}$, modified second-order rate coefficient $\left(\mathrm{h}^{-1}\right) ; b_{1 m}$, constant; $k_{1 R}$, Ritchie second-order rate coefficient $\left(\mathrm{h}^{-1}\right) ; k_{\mathrm{ex}}$, exponential rate coefficient $(\mathrm{mg} / \mathrm{g}) ; k_{m}$, mixed first-, second-order rate coefficient $\left(\mathrm{h}^{-1}\right) ; f_{2}$, involvement of pseudo-second-order model; $k_{\mathrm{fm}}$, fractal-like mixed first-, second-order rate coefficient $\left(\mathrm{h}^{-1}\right)^{\alpha} ; t^{\alpha}$, fractal time; $k_{\mathrm{ff}}$, fractal-like pseudo-first-order kinetic rate coefficient $\left(\mathrm{h}^{-1}\right) ; k_{\mathrm{fs}}$, fractal-like, pseudo-secondorder kinetic rate coefficient $\left(\mathrm{h}^{-1}\right) ; k_{\text {fex }}$, fractal-like exponential rate coefficient $\left(\mathrm{h}^{-1}\right) ; t_{\mathrm{bws}, \alpha}$, time required for adsorbing half the maximum amount; $n_{\mathrm{bws}}$, fractional reaction order

Acknowledgements The financial support from the Ministry of Human Resource Development (MHRD; New Delhi), Government of India, and the Department of Chemical Engineering and Institute Instrumentation Center of Indian Institute of Technology Roorkee,
India, for providing the facilities and technical support are gratefully acknowledged. The thoughtful comments by the Editor in Chief and two unknown reviewers are highly appreciated.

\section{References}

1. Aksu Z, Yener JA (2001) Comparative adsorption/biosorption study of mono-chlorinated phenols onto various sorbents. Waste Manag 21:695-702

2. Busca G, Berardinelli S, Resini C, Arrighi L (2008) Technologies for the removal of phenol from fluid streams: a short review of recent developments. J Hazard Mater 160:265-288

3. Calace N, Nardi E, Petronio BM, Pietroletti M (2002) Adsorption of phenols by papermill sludges. Environ Pollut 118:315-319

4. Desai JD, Ramakrishna C (1998) Microbial degradation of cyanides and its commercial application. J Sci Ind Res 57:441-453

5. Dash RR, Balomajumder C, Kumar A (2009) Removal of cyanide from water and wastewater using granular activated carbon. Chem Eng J 146:408-413

6. Patil YB, Paknikar KM (2000) Development of a process for biodetoxification of metal cyanides from wastewater. Process Biochem 35:1139-1151

7. Patil YB, Paknikar KM (2000) Biodegradation of silver-cyanide from electroplating industry waste water. Lett Appl Microbiol 30: 33-37

8. Bulgariu L, Bulgariu D (2011) Extraction of gold (III) from chloride media in aqueous polyethylene glycol-based two-phase system. Sep Purif Technol 80:620-625

9. Lakshmanraj L, Gurusamy A, Gobinath MB, Chandramohan R (2009) Studies on the biosorption of hexavalent chromium from aqueous solutions by using boiled mucilaginous seeds of Ocimum americanum. J Hazard Mater 169:1141-1145

10. Dash RR, Dash RR, Balomajumdar C (2014) Treatment of cyanide bearing effluents by adsorption, biodegradation and combined processes: effect of process parameters. Desalin Water Treat 52:3355-3366

11. Girish CR, Ramachandra Murty V (2014) Adsorption of phenol from aqueous solution using Lantana camara, forest waste: kinetics isotherm, and thermodynamic studies. Int Sch Res Not:1-14

12. Gupta N, Balomajumder C, Agarwal VK (2013) Adsorptive treatment of cyanide-bearing wastewater: a prospect for sugar industry waste. Chem Eng Comm 200:993-1007

13. Singh N, Balomajumder C (2016) Continuous packed bed adsorption of phenol and cyanide onto modified rice husk: an experimental and modeling study. Desal Water Treat 57:23903-23917

14. Vedula RK, Dalal S, Majumder CB (2013) Bioremoval of cyanide and phenol from industrial wastewater: an update. Biorem J 17(4): 278-293

15. Srivastava VC, Swamy MM, Mall ID, Prasad B, Mishra IM (2006) Adsorptive removal of phenol by bagasse fly ash and activated carbon: equilibrium, kinetics and thermodynamics colloids and surfaces a: Physicochem. Eng Aspects 272:89-104

16. Kilic M, Varol EA, Putun AE (2011) Adsorptive removal of phenol from aqueous solutions on activated carbon prepared from tobacco residues: equilibrium, kinetics and thermodynamics. J Hazard Mater 189(1-2):397-403

17. APHA (2001) Standard methods for the examination of water and wastewater, 20th ed. American Public Health Association, Washington, D.C.

18. Katyal S, Thambimuthu K, Valix M (2003) Carbonation of bagasse in a fixed bed reactor: influence of process variables on char yield and characteristics. Renew Energy 28(5):713-725

19. Brunauer S, Emmett PH, Teller E (1938) Adsorption of gases in multimolecular layers. J Am Chem 60(2):309-319 
20. Hameed BH, Tan IAW, Ahmad AL (2008) Adsorption isotherm, kinetic modeling and mechanism of 2,4,6-trichlorophenol on coconut husk-based activated carbon. Chem Eng J 144(2):235-244

21. Jung M, Ahn K, Lee Y, Kim K, Rhee J, Park JT, Paeng K (2001) Adsorption characteristics of phenol and chlorophenols on granular activated carbons (GAC). Microchem J 70:123-131

22. Mondal P, Balomajumder C (2007) Treatment of resorcinol and phenol bearing waste water by simultaneous adsorption biodegradation (SAB): optimization of process parameters. Int $\mathrm{J}$ Chem React Eng 5:51-58

23. Agarwal B, Balomajumdar C (2013) Simultaneous adsorption and biodegradation of phenol and cyanide in multicomponent system. Inter J Env Engg Manag 4:233-238

24. Stavropoulos GG, Skodras GS, Papadimitriou KG (2015) Effect of solution chemistry on cyanide adsorption in activated carbon. App Ther Engg 74:182-185

25. Swamy MM (1998) Studies on the treatment of phenolic wastewaters using adsorption and immobilized whole cells. In: Ph.D. Thesis. University of Roorkee, India

26. Radhika M, Palanivelu K (2006) Adsorptive removal of chlorophenols from aqueous solution by low cost adsorbent-kinetics and isotherm analysis. J Hazard Mater 138:116-124

27. Li H, Huang G, An C, Hu J, Yang S (2013) Removal of tannin from aqueous solution by adsorption onto treated coal fly ash: kinetic, equilibrium, and thermodynamic studies. Ind Eeg Chem Res 52: 15923-15931

28. Mall ID, Upadhyay SN, Sharma YC (1996) A review on economical treatment of wastewaters and effluents by adsorption. Int $\mathrm{J}$ Environ Stud 51:77-124

29. Oguz E (2005) Adsorption characteristics and the kinetics of the Cr(VI) on the Thuja oriantalis. Colloid Surf 252:121-128

30. Redlich O, Peterson DL (1959) A useful adsorption isotherm. J Phys Chem 63:1024-1024

31. Weber TW, Chakravorti RK (1974) Pore and solid diffusion models for fixed-bed adsorbers. J Am Inst Chem Engg 20:228-238

32. Leitao A, Serrao R (2005) Adsorption of phenolic compounds from water on activated carbon: prediction of multicomponent equilibrium isotherms using single-component data. Adsorption 11:167-179
33. Mohan D, Chander S (2001) Single component and multicomponent metal ions adsorption by activated carbons. Colloids Surf A Physicochem Eng Asp 177:183-196

34. Michalak I, Chojnacka K, Witek-Krowiak A (2013) State of the art for the biosorption process - a review. Appl Biochem Biotechnol 170:1389-1416

35. Haerifar M, Azizian S (2013) An exponential kinetic model for adsorption at solid/solution interface. Chem Eng J:65-71

36. Ncibi MC (2008) Applicability of some statistical tools to predict optimum adsorption isotherm after linear and non-linear regression analysis. J Hazard Mater 153:207-212

37. Leechart P, Nakbanpote W, Thiravetyan P (2009) Application of 'waste' wood-shaving bottom ash for adsorption of azo reactive dye. J Environ Manag 90(2):912-920

38. Vaghetti JCP, Lima EC, Royer B, Cardoso NF, Martins B, Calvete T (2009) Pecan nutshell as biosorbent to remove toxic metals from aqueous solution. Sep SciTechnol 44:615-644

39. Depci T (2012) Comparison of activated carbon and iron impregnated activated carbon derived from Golbasi lignite to remove cyanide from water. Chem Eng J 181:467-478

40. El-Aila HJ, Elsousy KM, Hartany KA (2011) Kinetics, equilibrium, and isotherm of the adsorption of cyanide by MDFSD. Arab J Chem. doi:10.1016/j.arabjc.2011.03.002

41. Moussavi G, Khosravi R (2010) Removal of cyanide from wastewater by adsorption onto pistachio hull wastes: parametric experiments, kinetics and equilibrium analysis. J Hazard Mater 183(1): 724-730

42. Noroozifar M, Khorasani-Motlagh M, Fard PA (2009) Cyanide uptake from wastewater by modified natrolite zeolite-iron oxyhydroxide system: application of isotherm and kinetic models. J Hazard Mater 166(2):1060-1066

43. Abdelkreem M (2013) Adsorption of phenol from industrial wastewater using olive mill waste. APCBEE Procedia 5(1):349-357

44. Alinnor IJ, Nwachukwu MA (2012) Removal of phenol from aqueous solution onto modified fly ash. Inter J Res Chem Environ 2: 124-129 